\title{
Hypertension and chronic kidney disease is highly prevalent in elderly patients with colorectal cancer undergoing primary surgery
}

\author{
Leszek Kozłowski, ${ }^{1, A-F}$, Klaudia Kozłowska 2,B,E,F, Jolanta Małyszko, ${ }^{3, A, C-F}$ \\ ${ }^{1}$ Department of Oncological Surgery, Cancer Center, Białystok, Poland \\ $22^{\text {nd }}$ Department of Nephrology, Medical University of Bialystok, Poland \\ ${ }^{3}$ Department of Nephrology, Dialysis and Internal Medicine, Medical University of Warsaw, Poland \\ A - research concept and design; B - collection and/or assembly of data; C - data analysis and interpretation; \\ $D$ - writing the article; $E$ - critical revision of the article; $F$ - final approval of the article
}

\section{Address for correspondence}

Jolanta Małyszko

E-mail:jolmal@poczta.onet.pl

Funding sources

None declared

Conflict of interest

None declared

Received on July 15, 2018

Reviewed on November 2, 2018

Accepted on February 18, 2019

Published online on August 30, 2019

\begin{abstract}
Background. Colorectal cancer (CRC) is a common and lethal disease. Hypertension is the most commonly reported comorbidity among cancer patients. Data on its incidence and prevalence is very scarce.

Objectives. The aim of the study was to evaluate the prevalence of hypertension and chronic kidney disease (CKD) in a cohort of 100 consecutive patients with CRC undergoing primary surgical treatment.
\end{abstract}

Material and methods. The pilot study included 100 consecutive patients with CRC undergoing primary surgery with curative intent within 1 year in the Department of Oncological Surgery in Białystok, Poland. No neoadjuvant therapy was administered before the surgery.

Results. The prevalence of hypertension was $62 \%$ among the patients studied. Sixty-five percent of the patients were older than 65 years and hypertension was present in $78 \%$ of these elderly patients. The prevalence of CKD was 15\%, while that of diabetes was 23\%. All CKD patients were older than 65 years of age. The hypertensive patients were more likely to be older and anemic with higher serum fibrinogen, which reflects a general inflammatory state. Elderly hypertensive patients had significantly higher creatinine levels, lower estimated glomerular filtration rate (eGFR) levels $(p<0.001)$ and lower platelet counts.

Conclusions. It is of the utmost importance for oncology patients to have any hypertension diagnosed and treated appropriately in order to prevent complications so they may continue their therapy with the least interruption or discontinuation of treatment and to ensure the best possible outcomes.

Key words: surgery, colorectal cancer, hypertension, chronic kidney disease, elderly

Cite as

Kozłowski L, Kozłowska K, Małyszko J. Hypertension and chronic kidney disease is highly prevalent in elderly patients with colorectal cancer undergoing primary surgery. Adv Clin Exp Med. 2019;28(10):1425-1428. doi:10.17219/acem/104537

DOI

10.17219/acem/104537

\section{Copyright}

Copyright by Author(s)

This is an article distributed under the terms of the

Creative Commons Attribution Non-Commercial License

(http://creativecommons.org/licenses/by-nc-nd/4.0/) 


\section{Introduction}

Colorectal cancer (CRC) is a common and lethal disease, the $3^{\text {rd }}$ most commonly diagnosed cancer in males and the $2^{\text {nd }}$ most common in females, though the incidence varies markedly. ${ }^{1}$ Surgery is the only curative modality for localized colon cancer. For patients who have undergone potentially curative resection of a colon cancer, the goal of postoperative (adjuvant) chemotherapy is to eradicate micrometastases, thereby reducing the likelihood of disease recurrence and increasing the chances of recovery. ${ }^{2}$ Chemotherapy carries a risk of significant toxicities, including emesis, diarrhea, febrile neutropenia, and cardiotoxicity. The frequency and severity of these side effects vary according to the specific drugs used and to the mode of administration. Hypertension is the most commonly reported comorbidity in cancer patients, with a rising incidence that is in line with the aging population of the developed world. ${ }^{1}$ In addition, it is also the most common comorbidity reported in cancer registries. ${ }^{1}$ However, detailed data on its incidence and prevalence is very scarce. Chemotherapy is a cardiovascular risk factor, particularly when combined with radiotherapy, which is responsible for increasing the incidence of cardiovascular events. ${ }^{3}$ The aim of this study was to evaluate the prevalence of hypertension and chronic kidney disease (CKD) in a cohort of patients with CRC undergoing primary surgical treatment with curative intent.

\section{Patients and methods}

The pilot study included 100 consecutive patients with CRC undergoing primary surgery with curative intent within 1 year in the Department of Oncological Surgery in Białystok, Poland. No neoadjuvant therapy was administered before the surgery. The analyzed data came from the demographic, clinical and laboratory parameters from medical charts. Blood pressure was measured with standard protocols. Hypertension was defined as either a blood pressure of at least $140 / 90 \mathrm{~mm} \mathrm{Hg}$ or the use of hypotension medication. Chronic kidney disease was defined according to the 2012 Kidney Disease: Improving Global Outcomes (KDIGO) guidelines, ${ }^{4}$ with estimated glomerular filtration rate (eGFR) estimated using the Chronic Kidney Disease Epidemiology Collaboration (CKD-EPI) formula. ${ }^{5}$

The study was approved by the appropriate ethics review board. The data were analyzed using STATISTICA v. 13.1 software (StatSoft Inc., Tulsa, USA). The normality of variable distribution was tested using the Shapiro-Wilk W test. Student's t-test was used in statistical analysis to compare differences between groups, with a p-value $<0.05$ considered statistically significant (when appropriate).

\section{Results}

The prevalence of hypertension among all of the patients studied was $62 \%$, but among the elderly patients it was $78 \%$. The mean age of the study population was $67 \pm 11$ years; $65 \%$ of the patients were older than 65 years. The prevalence of diabetes was $23 \%$, while the prevalence of CKD was $15 \%$. All CKD patients were older than 65 years of age. The clinical characteristics of the studied patients is shown in Table 1. The hypertensive patients tended to be older and anemic with higher serum fibrinogen, which reflects a general inflammatory state. When we grouped the patients according to age ( $\leq 65$ years vs $>65$ years) and presence of hypertension, the elderly hypertensive patients had significantly higher serum creatinine levels $(79.56 \pm 22.1 \mu \mathrm{mol} / \mathrm{L} \mathrm{vs}$ $70.72 \pm 21.22 \mu \mathrm{mol} / \mathrm{L} ; \mathrm{p}<0.01)$, lower corresponding eGFR levels according to the CKD-EPI formula $(75.5 \pm 15.97 \mathrm{~mL} /$ $\left.\mathrm{min} / 1.72 \mathrm{~m}^{2} \mathrm{vs} 95.72 \pm 18.00 \mathrm{~mL} / \mathrm{min} / 1.72 \mathrm{~m}^{2} ; \mathrm{p}<0.001\right)$, higher red blood cell distribution width (RDW) (14.8 $\pm 3.45 \%$ vs $13.49 \pm 2.69 \%$; $<<0.05)$, and lower platelet counts $\left(248.17 \pm 106.21 \times 10^{9} / \mathrm{L}\right.$ vs $\left.299.50 \pm 140.36 \times 10^{9} / \mathrm{L} ; \mathrm{p}<0.05\right)$.

Table 1. Clinical and biochemical data of colorectal cancer (CRC) patients with and without hypertension

\begin{tabular}{|c|c|c|}
\hline Parameter & $\begin{array}{l}\text { No hypertension } \\
\qquad(n=54)\end{array}$ & $\begin{array}{l}\text { Hypertension } \\
\qquad(n=46)\end{array}$ \\
\hline Age [years] & $64.51 \pm 1.62$ & $69.61 \pm 7.73^{*}$ \\
\hline $\mathrm{BMI}\left[\mathrm{kg} / \mathrm{m}^{2}\right]$ & $26.98 \pm 5.51$ & $28.52 \pm 3.48$ \\
\hline Sodium [mmol/L] & $139.25 \pm 2.86$ & $139.54 \pm 2.72$ \\
\hline Potassium [mmol/L] & $4.44 \pm 0.49$ & $4.35 \pm 0.55$ \\
\hline Hematocrit [\%] & $36.48 \pm 6.23$ & $39.27 \pm 5.12^{*}$ \\
\hline Hemoglobin [g/L] & $117.8 \pm 27.5$ & $130.4 \pm 19.1^{*}$ \\
\hline Erythrocyte count $\left[\times 10^{12} / \mathrm{L}\right]$ & $4.30 \pm 0.47$ & $4.49 \pm 0.49^{*}$ \\
\hline $\operatorname{MCV}[\mathrm{fl}]$ & $91.32 \pm 4.91$ & $104.11 \pm 10.26$ \\
\hline $\mathrm{MCH}[\mathrm{pg}]$ & $29.02 \pm 2.91$ & $27.28 \pm 4.29^{*}$ \\
\hline RDW [\%] & $11.60 \pm 6.96$ & $12.18 \pm 1.33$ \\
\hline Leukocyte count $\left[10^{9} / \mathrm{L}\right]$ & $7.21 \pm 3.51$ & $7.41 \pm 2.54$ \\
\hline Platelet count $\left[10^{9} / \mathrm{L}\right]$ & $267.11 \pm 101.88$ & $241.38 \pm 118.45$ \\
\hline Creatinine $[\mu \mathrm{mol} / \mathrm{L}]$ & $78.68 \pm 22.10$ & $80.44 \pm 22.10$ \\
\hline Urea [mmol/L] & $6.11 \pm 0.34$ & $5.59 \pm 1.62$ \\
\hline eGFR by CKD-EPI [mL/min/1.72 m²] & $84.59 \pm 21.23$ & $80.77 \pm 16.76$ \\
\hline APTT $[s]$ & $31.78 \pm 4.17$ & $30.91 \pm 6.03$ \\
\hline INR & $1.06 \pm 0.21$ & $1.05 \pm 0.25$ \\
\hline Fibrinogen $[\mu \mathrm{mol} / \mathrm{L}]$ & $9.79 \pm 2.15$ & $10.76 \pm 2.14^{*}$ \\
\hline Glucose [mmol/L] & $6.02 \pm 1.42$ & $6.38 \pm 1.30$ \\
\hline Pulse pressure [mm Hg] & $47 \pm 12$ & $50 \pm 14$ \\
\hline Mean arterial pressure [mm Hg] & $97 \pm 10$ & $104 \pm 11$ \\
\hline
\end{tabular}

$\mathrm{BMI}$ - body mass index; MCV - mean corpuscular volume; $\mathrm{MCH}$ - mean content of hemoglobin, aptt activated partial thromboplastin time; RDW - red blood cell distribution width; eGFR - estimated glomerular filtration rate; CKD-EPI - Chronic Kidney Disease Epidemiology Collaboration formula; APTT - activated partial thromboplastin time; INR - international normalized ratio. Conversion factors to SI units are as follows: for glucose -0.0555 , for creatinine -88.4 , for hemoglobin -10 , for fibrinogen -0.0294 , and for urea -0.357 ; $^{*} \mathrm{p}<0.05$. 


\section{Discussion}

In our study, in patients with CRC, the prevalence of hypertension was very high. It was even higher, reaching $78 \%$, in patients older than 65 years. Fraeman et al. ${ }^{6}$ estimated incidence rates of new-onset hypertension in 25,090 adult cancer patients ( $16 \%$ of whom had CRC) and found that crisis-level hypertension (systolic blood pressure $>180 \mathrm{~mm} \mathrm{Hg}$ or diastolic blood pressure $>120 \mathrm{~mm} \mathrm{Hg}$ ) was most commonly seen in patients treated for gastric, ovarian, lung, and CRCs. New-onset hypertension was observed during active treatment in about $1 / 3$ of the cancer patients. However, data on the prevalence of hypertension in CRC is very limited. In addition, all of the patients with CKD were over 65 years of age.

In a cohort of patients with CRC in Oman, the prevalence of hypertension was $42 \%$ and the prevalence of diabetes was $25 \% .^{7}$ Their population was younger (56 years) than ours (mean age: 67 years). In another study on 138 patients with CRC in Malaysia, the prevalence of type 2 diabetes and hypertension was $13 \%$ and $34.8 \%$, respectively. ${ }^{8}$ The prevalence of hypertension and type 2 diabetes in relatively young patients (mean age: 53 years) with CRC in Iran was $13.38 \%$ and $8.69 \%$, respectively. ${ }^{9}$ It should be stressed that the vast majority of published studies report the effects of CRC treatment and the incidence of adverse events, while data on the prevalence of hypertension and other comorbidities at the time of diagnosis or surgery is lacking. An updated systematic review and comparative metaanalysis by Abdel-Rahman et al. ${ }^{10}$ included randomized phase II and phase III trials of patients with solid tumors treated with sunitinib, axitinib, cediranib, or regorafenib describing daily events of hypertension, left ventricular dysfunction, bleeding, or thrombosis. Patients treated with these 4 agents had a significantly increased risk of all-grade hypertension and bleeding. ${ }^{11}$ However, the data on the prevalence of hypertension before the therapy was not presented. Abdel-Qadir et al. ${ }^{11}$ evaluated 77 phase III randomized, controlled trials and reported that angiogenesis inhibitors increased the risk of hypertension, arterial thromboembolism, cardiac ischemia, and cardiac dysfunction. Falchook et al. ${ }^{12}$ studied patients with advanced solid tumors - including CRC - which were refractory to standard therapy who were treated with a combination of bevacizumab and sorafenib. Two-thirds of the patients experienced adverse events of grade 2 or higher, most commonly hand and foot syndrome $(\mathrm{n}=27 ; 24 \%)$ and hypertension ( $\mathrm{n}=24 ; 21 \%)$.

The prevalence of CKD was reported to be high in patients with solid tumors, ${ }^{13}$ but the data is also limited. A high prevalence of CKD was reported in 2 other studies as well: $\sim 33 \%$ and $27 \%{ }^{14,15}$ In the Belgian Renal Insufficiency and Anticancer Medications study (BIRMA), impaired kidney function, i.e., an estimated Modification Diet in Renal Disease (eMDRD) of $<90 \mathrm{~mL} / \mathrm{min} / 1.73 \mathrm{~m}^{2}$ was reported in $59.5 \%$ of CRC cases. ${ }^{16}$ In a Korean retrospective study on 8,223 cancer patients with 1 or more serum creatinine measurements available, the CKD prevalence in CRC patients was $10.2 \%{ }^{17}$ This figure is slightly lower than in our study, most likely due to the younger age of the population studied ( $56 \pm 14$ years vs $67 \pm 11$ years). Moreover, as shown in this study, CKD was associated with an increase in the overall mortality rate of cancer patients (including breast cancer) - approx. 12\% - independent of other known risk factors. ${ }^{17}$ The possible associations between CKD, hypertension and malignancy were reviewed recently. ${ }^{18,19}$

Attention should also be paid to the limitations of our study, which consisted of a relatively small sample pooled in just 1 center. The population prevalence of hypertension and CKD was not compared with that of the group of patients with CRC. The fairly homogeneous study group and the lack of a control group might be considered limitations. As we did not perform any follow-up, we cannot indicate any specific benefits coming from paying special attention to the presence and appropriate treatment of any particular comorbidity.

It should be pointed out that large, randomized, controlled trials in general report hypertension as a side effect, but adding the prevalence of elevated blood pressure as a comorbidity would be of great clinical relevance. Newonset or worsening systemic hypertension can be found with numerous chemotherapeutics and is particularly common with antiangiogenic drugs. ${ }^{3}$ Therefore, the evaluation and treatment of hypertension is a practical starting point for the treatment of cardiotoxicity induced mainly by angiogenic inhibitors. It is of the utmost importance for oncology patients to have any hypertension diagnosed and treated appropriately in order to prevent complications so they may continue their therapy with the least interruption and no discontinuation of treatment and to ensure the best possible outcomes, as patients with early CRC and diabetes or hypertension have a significantly greater risk of cancer recurrence and death after treatment. ${ }^{9}$ In addition, as the prevalence of CKD and hypertension may be further exacerbated by adjuvant therapy, an assessment of kidney function is prerequisite before the introduction of adjuvant treatment.

\section{References}

1. Siegel RL, Miller KD, Jemal A. Cancer statistics, 2017. CA Cancer J Clin. 2017;67(1):7-30.

2. Sargent D, Sobrero A, Grothey A, et al. Evidence for cure by adjuvant therapy in colon cancer: Observations based on individual patient data from 20,898 patients on 18 randomized trials. J Clin Oncol. 2009; 27(6):872-877.

3. Herrmann J, Yang EH, lliescu CA, et al. Vascular toxicities of cancer therapies: The old and the new - an evolving avenue. Circulation. 2016;133(13):1272-1289.

4. KDIGO 2012 Clinical Practice Guideline for the Evaluation and Management of Chronic Kidney Disease. Kidney Int Suppl (2011). 2013;3(1): $1-163$.

5. Levey AS, Stevens LA, Schmid CH, et al; CKD-EPI (Chronic Kidney Disease Epidemiology Collaboration). A new equation to estimate glomerular filtration rate. Ann Intern Med. 2009;150(9):604-612. 
6. Fraeman $\mathrm{KH}$, Nordstrom BL, Luo W, Landis $\mathrm{SH}$, Shantakumar S. Incidence of new-onset hypertension in cancer patients: $A$ retrospective cohort study. Int J Hypertens. 2013;2013:379252.

7. Kumar S, Burney IA, Zahid KF, et al. Colorectal cancer patient characteristics, treatment and survival in Oman: A single center study. Asian Pac J Cancer Prev. 2015;16(12):4853-4858.

8. Othman $\mathrm{NH}$, Zin AA. Association of colorectal carcinoma with metabolic diseases: Experience with 138 cases from Kelantan, Malaysia. Asian Pac J Cancer Prev. 2008;9(4):747-751.

9. Ahmadi A, Mobasheri M, Hashemi-Nazari SS, Baradaran A, Choobini ZM. Prevalence of hypertension and type 2 diabetes mellitus in patients with colorectal cancer and their median survival time: A cohort study. J Res Med Sci. 2014;19(9):850-854.

10. Abdel-Rahman O, Fouad M. Risk of cardiovascular toxicities in patients with solid tumors treated with sunitinib, axitinib, cediranib or regorafenib: An updated systematic review and comparative meta-analysis. Crit Rev Oncol Hematol. 2014;92(3):194-207.

11. Abdel-Qadir H, Ethier JL, Lee DS, Thavendiranathan P, Amir E. Cardiovascular toxicity of angiogenesis inhibitors in treatment of malignancy: A systematic review and meta-analysis. Cancer Treat Rev. 2017;53: 120-127.

12. Falchook GS, Wheler JJ, Naing A, et al. Dual antiangiogenic inhibition: A phase I dose escalation and expansion trial targeting VEGF-A and VEGFR in patients with advanced solid tumors. Invest New Drugs. 2015;33(1):215-224.
13. Launay-Vacher V. Epidemiology of chronic kidney disease in cancer patients: Lessons from the IRMA study group. Semin Nephrol. 2010; 30(6):548-556. doi:10.1016/j.semnephrol.2010.09.003

14. Dogan E, Izmirli M, Ceylan K, et al. Incidence of renal insufficiency in cancer patients. Adv Ther. 2005;22(4):357-362.

15. Launay-Vacher V, Izzedine H, Rey JB, et al. Incidence of renal insufficiency in cancer patients and evaluation of information available on the use of anticancer drugs in renally impaired patients. Med Sci Monit. 2004;10:CR209-212.

16. Janus $N$, Launay-Vacher V, Byloos $E$, et al. Cancer and renal insufficiency results of the BIRMA study. Br J Cancer. 2010;103(12):1815-1821.

17. Na SY, Sung JY, Chang JH, et al. Chronic kidney disease in cancer patients: An independent predictor of cancer-specific mortality. Am J Nephrol. 2011;33(2):121-130.

18. Małyszko J, Kozłowski L, Kozłowska K, Małyszko M, Małyszko J. Cancer and the kidney: Dangerous liaisons or price paid for the progress in medicine? Oncotarget. 2017;8(39):66601-66619.

19. Małyszko J, Małyszko M, Kozłowski L, Kozłowska K, Małyszko J. Hypertension in malignancy: An underappreciated problem. Oncotarget. 2018;9(29):20855-20871. 